\title{
EL ABSOLUTO LITERARIO DE LA POESÍA DE ALEJANDRA PIZARNIK
}

\section{The Absolut Literary of Alejandra Pizarnik's Poetry}

\author{
VÍCTOR VICH \\ Pontificia Universidad Católica del Perú (Perú) \\ vvich@pucp.pe \\ ORCID: https://orcid.org/0000-0003-4192-6873
}

\section{Resumen}

Este ensayo sostiene que la búsqueda de un absoluto guía la estética de Alejandra Pizarnik. Se trata de una voz que no duda en cruzar las fronteras del yo con el objetivo de asumir todo aquello que la razón oculta y de confrontarse con todo aquello que al lenguaje le es imposible decir y hacer. El ensayo sostiene, sin embargo, que esa derrota trae consigo la emergencia de un nuevo absoluto que no es otra cosa que el propio poema. La pérdida del absoluto termina siendo constitutiva de un nuevo "absoluto literario".

\section{Palabras clave}

Poesía hispanoamericana, Alejandra Pizarnik, romanticismo/absoluto

\section{Abstract}

This essay argues that the search for an "absolute" guides Alejandra Pizarnik's aesthetics. It is a voice that does not hesitate to cross the borders of self in order to assume everything that reason hides and to confront everything that language is unable to say and do. The essay argues, however, that this defeat brings with it the emergence of a new absolute that is none other than the poem itself. The loss of the absolute ends up being constitutive of a new "literary absolute". 


\title{
Keywords
}

Hipanoamerican Poetry, Alejandra Pizarnik, Romanticism/Absolute

\author{
Quisiera electrizar mis ojos y sacudirles \\ su inercia doméstica
}

\section{Alejandra Pizarnik, Diarios (2005)}

El lugar de enunciación de la poesía de Alejandra Pizarnik es el desgarro: su manera de concebir el arte y su forma de posicionarse ante la vida es fundamentalmente romántica. La voz que da forma a sus poemas está marcada por la búsqueda de un absoluto. "Soy una convulsión, un grito, sangre aullando", escribió en uno de sus primeros diarios (Pizarnik, 2005: 105). Lukács llamó "romanticismo de la decepción" a un conjunto de representaciones en las que no existe adecuación entre la realidad y el alma porque "el alma se ha vuelto demasiado amplia en relación al destino que la vida pueda ofrecerle" (2010: 108). En efecto, las imágenes de esta poesía no se cansan de mostrar el fracaso ante la revelación de algo trascendente. Esta es una poesía que no duda en hacer pública su sed de infinito, pero también su triste derrota.

De todas formas, terca en su búsqueda, nos encontramos ante una voz que está dispuesta a cruzar las fronteras del yo y del lenguaje. De un lado, cruzar al yo implica confrontarse con una dimensión que fuerza a asumir todo aquello que la razón oculta bajo una máscara de equilibrio y unidad. De otro, cruzar al leguaje implica confrontarse con el abismo del deseo, con la falta y con todo aquello que le es imposible decir y que está impedido de hacer. El semblante del yo y la estructura misma del lenguaje son, para esta poesía, una condena y un obstáculo:

Pizarnik delata una profunda incomodidad ante su propio discurso poético [...] Su crítica de la palabra es absoluta. La mantiene al borde del silencio minando la seguridad que todo poeta incluso el más escéptico — necesita para seguir escribiendo [...] Pizarnik no logra convencerse que sus palabras puedan otorgar validez a su empresa poética. Esta terrible duda la acompaña desde sus primeros poemas y, con creciente influjo, va apoderándose de ella hasta imponerse como el tema central de su poesía. (Lasarte, 1983: 867)

La exploración de la noche es el motivo central a partir del cual va a configurarse buena parte de esta poesía. La noche, como sabemos, es un momento de suspensión de la ley y del orden; un lugar para la producción de un mito situado más allá de la racionalidad utilitaria. La noche emerge como un lugar de revelación de la verdad, vale decir, como la posibilidad de llegar a tener un encuentro con lo más auténtico del ser (Béguin, 1981: 32). De hecho, la tradición poética siempre ha nombrado a la noche como aquel lugar, o momento, donde los poetas escuchan una especie de "llamado" que solo ellos pueden recibir. Novalis (1998) describió a la noche como una especie de "otro" de la razón, como aquello absoluto que trae consigo la posibilidad de otra vida. En sus famosos himnos, la noche quedó representada como una reina protectora donde los ojos pueden ver más lejos y donde es posible percibir la unidad del todo. "En la noche sucede la noche" (2005: 197), escribió Pizarnik en otro de sus diarios. Desde ahí, pasemos entonces a comentar un poema de Alejandra Pizarnik titulado "Algo":

noche que te vas

dame la mano

obra de ángel bullente

los días se suicidan 
¿por qué?

noche que te vas

buenas noches. (Pizarnik, 2015: 50)

¿Está la noche personificada en este poema? Sí, en tanto aparece como una instancia a la que se le dirige un discurso. Sí, en tanto la construcción vocativa antecede a una cláusula que la carga de agencia. A diferencia de lo que afirmaría el sentido común, la noche es aquí entendida como la vida misma y el día como la muerte. Los días se suicidan porque saben que no han sido construidos por un “ángel bullente" y porque están lejos de activar una absoluta intensidad; se suicidan porque saben que no pueden ser como la noche.

Notemos que la primera imagen del poema puede tener, al menos, dos posibilidades de lectura: como pedido y como lamento. Como pedido, se solicita una revelación, vale decir, la necesidad de contacto con algo verdadero. Como lamento, se trata de la profunda desesperación ante una pérdida. “Tú, noche, que me has revelado algo, no te vayas, quiero seguir estando contigo" puede ser una manera de parafrasear el verso. El romanticismo - lo ha sostenido Groys - supuso "una nostalgia que no puede ser satisfecha por lo finito" (2008: 21) pues el deseo de absoluto, esa sed, deja siempre a la voz poética en un grave vacío metafísico.

En ese sentido, el poema afirma que la noche se retira; muestra que nada puede detenerla y que no hay posibilidad de interferir en su rumbo. Desde ahí, la consecuencia será catastrófica: el sujeto queda desprendido de ella y su estado será sumamente doliente. Con esta partida, se pierde entonces la imaginación, el deseo, la posibilidad de infinito. El desconcierto será grave y, ante dicha situación, no queda sino abrirle paso al discurso irónico. Al decir "buenas noches", la voz poética se despide de toda revelación posible (de la verdad, de la belleza y del absoluto) y sitúa a los lectores ante la dolorosa contemplación del vacío. En esta poesía, la ironía se vuelve "el arma que deconstruyendo la saturación de sentido, dicta el non sense. En consecuencia, lo que hace reír a quien escribe no es ningún chiste para quien lo lee" (Kamenzain, 2007: 91).

Si pensamos en una lectura que apunte a un referente exterior (casi imposible en Pizarnik) se trata, en realidad, de la constatación de un mundo — de una realidad social- que ya no podrá encantarse. En estos versos, en efecto, en el día no hay encantamiento posible porque el día está gobernado por la razón, el orden y el poder. La noche, por el contrario, siempre nombra la presencia de lo transgresor y lo divino. Sin embargo, a diferencia del tópico que entiende la noche como aquello que precede a una manifestación divina (Post tenebras spero lucem) aquí la noche se basta a sí misma pues ella es la revelación misma: "Toda la noche hago la noche", escribió la autora en otro poema (Pizarnik, 2015: 215). El interés que esta poesía tiene por la noche trae consigo un verdadero desprecio del día. Un nuevo texto, titulado "El corazón de lo que existe", insiste en estas imágenes:

No me entregues tristísima medianoche

Al impuro mediodía blanco (Pizarnik, 2015: 186)

Situada en una condición límite, notemos que se trata de una voz que reconoce que pronto va a quedar inscrita en una situación desesperada o desesperante. El "impuro mediodía blanco" es todo lo opuesto al absoluto romántico; es aquello que excluye a lo irracional y al deseo. Nuevamente, el desgarro y la resignación se hacen presentes. Por eso, la enunciación es agónica porque surge como un intento para intentar retener a la noche y evadir lo artificioso del día. La voz poética la llama "tristísima" porque se está yendo y no parece posible poder detenerla. El blanco es aquí el color de la falta y del silencio: el signo de un vacío imposible de controlar. "Balada de la piedra que llora" dice lo siguiente: 
pero la muerte se muere de risa, pero la vida se muere de llanto pero la muerte pero la vida pero nada nada nada. (Pizarnik, 2015: 62)

¿Por qué ocurre esto? ¿Por qué se representa a la vida como un transcurrir muerto de pena? La repuesta no puede ser otra que porque en la vida hay un deseo insatisfecho. ¿Cuál es ese deseo? Ya lo hemos dicho: el deseo de absoluto, de revelación de lo trascendente, de un tipo de conocimiento capaz de resistir a la condición finita de lo humano.

La estructura anafórica a partir de la cual el poema ha sido escrito cumple la función de imprimirle una dimensión tanática. De hecho, el psicoanálisis nos ha enseñado que todo fracaso suele ser repetición. Por eso, la necesidad de repetir tres veces el pronombre "nada" da cuenta de la radical imposibilidad de encontrar un sentido pleno. La conjunción "pero", repetida cinco veces en el poema, establece, no una ilación, sino una disyunción y, por tanto, una crisis. Todo en este poema muestra una traba: algo que impide el fluir del sentido, algo que rompe toda secuencia y así produce una fricción siempre dolorosa.

Nuevamente, la ironía surge de la desproporción existente. La muerte "se muere de risa" y el sinsentido parece burlarse de aquel proyecto siembre en búsqueda de un absoluto que pueda llegar a instalarse definitivamente. La voz poética ha vuelto a reconocer que entre la vida y el absoluto existe una frontera que es imposible no tener en cuenta. Ese límite es marcado de una manera tajante en el siguiente poema:

Y es siempre el jardín de las lilas al otro lado del río. Si el alma

pregunta si queda lejos se le responderá: del otro lado, no éste sino aquel. (Pizarnik, 2015: 229)

Resulta claro que el aludido jardín es representado como la manifestación de la belleza en su estado más puro. Las lilas emergen como el signo de la perfección gratuita. Más allá de la precariedad de lo humano, aquí la naturaleza adquiere una significación absoluta. Sin embargo, la voz poética expresa la perturbación que sufre porque sabe que dicho lugar se encuentra "al otro lado del río". Es decir, ese jardín no se encuentra aquí sino allá, lejos de todo alcance posible. Ese jardín, en suma, no coincide con las posibilidades de su deseo: ella quisiera que el jardín se encuentre de este lado, pero se desgarra porque no es así. "Soy una enorme herida. No quiero preguntar por qué", escribió en otro lugar (Pizarnik, 2005: 81).

El punto, sin embargo, es que la locación del jardín instala un reto peligroso. En efecto, para acceder a él hay que cruzar una frontera y sabemos que todas ellas implican un riesgo. Se trata de la frontera abisal de la vida con la muerte. Por eso, el título del poema — "Rescate" — es significativo en tanto afirma que ese jardín se tuvo en algún momento, pero llegó a perderse por alguna razón desconocida. De hecho, la condición romántica de este poema (y de toda esta poesía) se constituye desde esa certeza: un artista así cree firmemente que hay algo perdido y que es urgente ir al rescate del absoluto; cree que la felicidad es recuperable si se es capaz de cruzar hacia el otro lado del río para retomar lo que fue propio. Una nueva imagen sobre este proceso podemos encontrarla en el poema titulado "La noche":

Poco sé de la noche

Pero la noche parece saber de mí

Y más aún, me asiste como si me quisiera,

me cubre la consciencia con sus estrellas

Tal vez la noche sea la vida y el sol la muerte

Tal vez la noche es nada

y las conjeturas sobre ella nada 
y los seres que la viven nada.

Tal vez las palabras sea lo único que existe

en el enorme vacío de los siglos

que nos arañan el alma con sus recuerdos.

Pero la noche ha de conocer la miseria

que bebe de nuestra sangre y de nuestras ideas.

Ella ha de arrojar odio a nuestras miradas

sabiéndolas llenas de intereses, de desencuentros.

Pero sucede que oigo a la noche llorar en mis huesos.

Su lágrima inmensa delira

y grita que algo se fue para siempre

Alguna vez volveremos a ser. (Pizarnik, 2015: 85)

En estas imágenes, la noche delira porque algo de ella se ha ido para siempre. La añoranza de infinito emerge a través del mito del "paraíso perdido" que, como puede notarse, es el tópico elegido para producir una figuración utópica. Nuevamente, la utopía surge como una esperanza de recuperación. Si el paraíso se ha perdido, eso supone sostener que la unidad sí llegó a existir y entonces habría que ir tras ella.

Esta es una voz que afirma saber muy poco de la noche, pero sostiene, sin embargo, que la noche sí sabe de ella. Preguntémonos entonces: ¿qué es lo que la noche sabe sobre la voz poética? En principio, sabe que está desgarrada por su falta y que está intentando recuperar su unidad y su sentido. Casi como una condolencia, los versos afirman que la noche la cuida y la cubre con sus estrellas. Por eso, se establece un tipo de complicidad entre ambas en tanto las dos están en busca de aquella unidad perdida que el romanticismo no se cansa de representar. Aunque en este poema nos enfrentamos ante una noche que ya no puede revelar nada, y que se encuentra angustiada por su nueva condición, la voz poética desea intensamente, con algo de fe, que la unidad pueda llegar a recuperarse: "Alguna vez volveremos a ser", dice.

Hablar de fe y de convicción es, sin embargo, algo muy problemático en la poética de Alejandra Pizarnik. En realidad, esta es una poesía que siempre está cuestionando sus propias suposiciones: ¿y si las palabras son solo el falso semblante de una plenitud inexistente? ¿Y si ellas son puras imágenes sin referente concreto? ¿Y si las palabras son solo "ese enorme vacío de los siglos que nos arañan el alma con sus recuerdos"? En la poesía de Alejandra Pizarnik, la búsqueda insistente es la manera agónica de lidiar con los intentos de construir una fe:

cultivo el jardín del furor

mi roja sed humeante señala el día. (Pizarnik, 2015: 355)

La subjetividad es aquí ansia y anhelo. Pero es también furor y agitación a causa de algún tipo de contrariedad. En este poema, la voz poética muestra todo su miedo, su conmoción, su opción por insistir en lo imposible, aunque ello solo la conduzca a quedar inserta bajo una "roja sed humeante". Sabemos bien que la vehemencia del artista romántico es la vehemencia de la eternidad y hacia lo trascendente. En esta poesía, la subjetividad no es otra cosa que esa vehemencia llena de furor.

Zona de la tensión perpetua.

Yo la atravesé con mi voz.

La atravesé en un misterioso gemido

Para solo llegar a una tensión perpetua

Desconocedora del sol y de sus milagros. (Pizarnik, 2015: 326) 
Es cierto que no hay miedo de cruzar una frontera, pero el problema es que no se llega a ningún lado. Es verdad que hay riesgo y apuesta, pero también que siempre se fracasa. La tragedia reside entonces en descubrir que todo esfuerzo parece conducir al mismo lugar. El camino, por tanto, deja de ser verdaderamente un camino para volverse una "tensión perpetua", un simple "gemido" o un círculo absurdo. Este poema muestra el desconcierto en el que todos los riesgos no parecen servir para nada. A pesar del esfuerzo realizado, de la voluntad y de la convicción plena, el poema termina por representar una voz que testimonia, con desgarro, la imposibilidad de conocer "al sol y a sus milagros". Por eso,

El viento muerde en mi herida

La noche mendiga en mi sangre. (Pizarnik, 2015: 86)

El verbo "muerde" se constituye como aquel elemento que dota al poema de una gran fuerza estética. Todo aquí es vampirismo y testimonio de suma debilidad. La subjetividad está herida, pero es ahí, en dicho lugar, donde ocurre una violencia mayor. Por si fuera poco, la noche también intenta tomar algo de la vida que subyace. Notemos que el título de poema - Nada - funciona como un reverso del absoluto. No se trata, exactamente, de la nada como un vacío sino más bien de una nada llena de hambre, una nada con demasiada nada: una nada absolutamente romántica. Para esta poesía, lo romántico emerge como la intensidad de esa nada. El problema es que esa nada ha ido tomándolo todo en la subjetividad y la voz poética no puede dejar de contemplar, con dolor, dicha presencia (o ausencia). Veamos un nuevo poema al respecto:

La muerte siempre al lado

Escucho su decir

Sólo me oigo. (Pizarnik, 2015: 188)

Como puede notarse, se produce aquí un giro sorprendente. Al principio, la muerte aparece representada como una realidad externa a la voz poética, pero, al final, termina por revelarse como una dimensión interior a sí misma. En efecto, aquí la muerte se ha convertido en la voz de una subjetividad que se ha descubierto minada internamente por ella. A la muerte, por tanto, se la reconoce como una muerte interior. "El lenguaje es para mí un muro, algo que me expulsa y me deja afuera" (Pizarnik, 2005: 286), escribió en otro lugar.

Si se retoma lo afirmado al inicio de este ensayo, se puede sostener como conclusión que el desagarro de esta poesía surge del intento por cruzar tanto los límites del yo como aquellos del lenguaje. El proyecto consistió en acercarse a esas dos fronteras que marcan una división entre algo presente y algo ausente, entre el consciente y el inconsciente, entre la inercia de la vida y el deseo salvaje de una intensidad absoluta.

Expliquémonos más. De un lado, nos encontramos ante una poesía que descubre que, tras la superficie del yo, existe una falta que lo descentra y que lo quiebra. De otro, observamos una voz que va confrontándose con las fronteras del lenguaje y con un conjunto de preguntas sobre la función de los símbolos. ¿Es posible convocar al absoluto a través de las palabras? ¿Es posible creer que detrás de las palabras, exista algo mayor? Por momentos, los poemas de Alejandra Pizarnik intentan afirmar que sí. El ímpetu romántico que la motiva busca imaginar que las palabras son — deberían ser- el efecto de algo mayor que estaría por detrás y que pudiera estar indicando una realidad efectivamente cargada de sentido.

El problema, sin embargo, es que se trata también de una poesía que, poco a poco, va perdiendo toda fe en la existencia del absoluto como una realidad exterior: en ese sentido, la opción por una austeridad retórica cada vez más radical no revela sino la opción por afirmar al silencio o a la nada como el soporte de todo lo existente. Esta es una poesía que termina por constatar que el silencio es el agente que opera dentro de la realidad y que es, probablemente, el fundamento mismo del lenguaje: "Te 
alejas de los nombres/que hila el silencio de las cosas" (Pizarnik, 2015: 130). En ese sentido, la angustia de estos versos es, en última instancia, una angustia frente a las bases mismas del lenguaje.

En síntesis, si a esta voz se le "revela" algo es fundamentalmente la imposibilidad del decir. Carente de sentido, "la existencia se expone haciendo de esta misma carencia su verdad misma" (Nancy, 2003: 112). Desde ahí, estos poemas descubren que lo verdadero de la existencia es la falta misma, no la sombra de algo que desconocemos, sino el semblante de algo que simplemente no existe. A causa de reconocer aquello, a causa de haber comenzado a asumirlo, los versos optaron por reducirse al mínimo y plegarse sobre sí mismos. En ese sentido, optaron por representar al absoluto como una huida, como una escapada, como algo capaz de llegar a un borde para dejar solo el desgarrado trazo de una ausencia. Esta es una poesía que construye toda su estética en la exposición de ese límite.

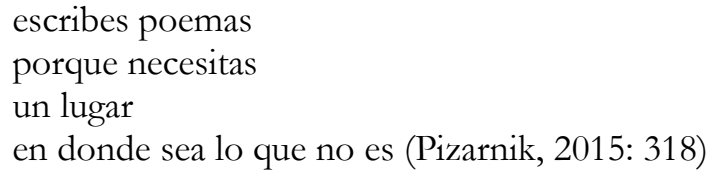

¿Es que lo que es "no es", o es que simplemente no lo podemos representar? No poderlo simbolizar, sin embargo, nunca significa el completo fracaso de esa voz. Más bien, podría decirse que esa derrota es también portadora de algo nuevo. Me explico mejor: entre la búsqueda y el fracaso, surge el propio poema como absoluto. El absoluto termina siendo entonces la propia literatura. Es el mismo texto poético el que encarna, y hace suyo, el absoluto romántico entendido como falta y como vacío.

El romanticismo implica la producción de algo inédito. El nombre de ese algo, a decir verdad, los románticos lo ignoran [...] pero hay que reconocer, en el pensamiento romántico, no solo el absoluto de la literatura, sino la literatura en tanto absoluto. (Lacoue-Labarthe y Nancy, 2012: 3334)

Todo poema es un absoluto porque adviene hacia un límite: "Explicar con palabras de este mundo/Que partió de mí un barco llevándome" (Pizarnik, 2015: 115). Ante la constatación de lo abisal y del silencio, emerge una "palabra inútilmente profunda" (Pizarnik, 2005: 455), pero verdadera al fin y al cabo. En ese sentido, el fracaso de la palabra poética no es exactamente un fracaso. Lo que se ha perdido del absoluto solo está perdido en el sentido en que esa pérdida es constitutiva del propio absoluto (Nancy, 2001: 30). Por eso, la experiencia sobre el no poder simbolizar concluye en una apertura hacia otro lugar. Ese algo es la poesía misma.

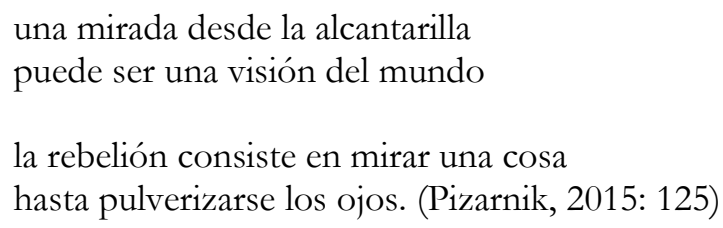

En la primera de sus quince tesis sobre el arte contemporáneo, Badiou (s/f) ha sostenido que el arte no es la irrupción de lo infinito en la condición finita de la vida, sino que, por el contrario, es la producción de una serie infinita mediante el medio finito de una operación material. Es esto, en mi opinión, lo que se representa y ocurre en el poema anterior. La condición absolutamente romántica de estos versos termina por producir una crítica sobre sí misma. La verdad ya no refiere a aquel absoluto que sería capaz de "descender" hacia la tierra sino al revés. Estos versos afirman que es, desde la inmanencia del presente, donde puede surgir lo trascendente; es desde lo puramente material donde el absoluto puede comenzar a emanar.

De todas formas, el sujeto de esta poesía no puede dejar de ser una falta y un desbalance. "Mi vida se llama carencia" (Pizarnik, 2005: 99), dijo. Sin embargo, la voz que emerge en sus poemas es una 
que "se levanta de un cadáver” (Dobry, 2004: 35). “¿Qué es entonces este vacío que me recorre? ¿Qué es entonces la nada que camina por mi ser?” (Pizarnik, 2005: 72). La respuesta a ello se encuentra en el poema anteriormente citado: el absoluto solo puede emerger como una grieta construida desde la propia carencia. Por eso cada poema es un poema post mortem y se vuelve, sobre todo, un lugar afirmativo (Kamenzain, 1996: 19). Desde ahí, al sentimiento nostálgico puede superponérsele otro distinto. Todo consiste en insistir en esa búsqueda de lo infinito dentro de lo finito, en esa falta de miedo a electrizarse los ojos.

\section{Bibliografía}

BADIOU, Alain (s/f). "Tesis sobre el arte contemporáneo", en Debates Ramónicas, p. 9. Consultado en <http://70.32.114.117/gsdl/collect/revista/index/assoc/HASH82d2/d5babb35.dir/r41_05nota.pdf $>(27 / 02 / 2021)$.

BEGUin, Albert (1981), El alma romántica y el sueño. Ensayo sobre el romanticismo alemán y la poesía francesa. Ciudad de México, Fondo de Cultura Económica.

Dorby, Edgardo (2004), "La poesía de Alejandra Pizarnik: una lectura de extracción de la piedra de la locura", en Cuadernos hispanoamericanos, 644, pp. 33-43.

Groys, Boris (2008), Bajo sospecha. Una fenomenología de los medios. Fontán del Junco, Manuel y Alejandro Martín Navarro (trads). Valencia, Pre-textos.

KAMENSZAIn, Tamara (2007), La boca de testimonio. Lo que dice la poesía. Buenos Aires, Norma.

KAMENSZAin, Tamara (1996), La edad de la poesía. Rosario, Beatriz Viterbo.

Lacoue-Labarthe, Philippe y Jean-Luc Nancy (2012), El absoluto literario. Teoría de la literatura en el romanticismo alemán. González, Cecilia y Laura Carugati (trads.). Buenos Aires, Eterna Cadencia.

LASARTE, Francisco (1983), "Más allá del surrealismo: la poesía de Alejandra Pizarnik", en Revista Iberoamericana, XLIX (125), pp. 867-877.

LUKÁCS, György (2010), Teoría de la novela. Un ensayo histórico filosófico sobre las formas de la gran literatuta épica. Ortelli, Micaela (trad.). Buenos Aires, Ediciones Godot.

NANCY, Jean-Luc (2003), La creación del mundo o la mundialización. Perera Velamazán, Pablo (trad.). Barcelona, Paidós.

NANCY, Jean-Luc (2001), La comunidad desobrada. Perera, Pablo; Herrera, Isidro y Alejandro del Río (trads.). Madrid, Arena.

Novalis (1998 [1800]), Himnos a la noche y cánticos espirituales. Ferrari, Américo (trad., intro y notas). Lima, PUCP.

PIZARNIK, Alejandra (2015), Poesía completa. Becciú, Ana (ed.). Buenos Aires, Lumen.

PIZARNIK, Alejandra (2005), Diarios. Becciú, Ana (ed.). Buenos Aires, Lumen. 